\title{
Optimisation of accelerated solvent extraction for screening of the health benefits of plant food materials
}

\author{
Reginald Wibisono ${ }^{1}$, Jingli Zhang ${ }^{1,{ }^{*}}$, Zaid Saleh${ }^{1}$, David E. Stevenson ${ }^{2}$, Nigel I. Joyce ${ }^{3}$ \\ ${ }^{1}$ The New Zealand Institute for Plant and Food Research Ltd, Auckland, New Zealand; Jingli.Zhang@plantandfood.co.nz \\ ${ }^{2}$ The New Zealand Institute for Plant and Food Research Ltd, Hamilton, New Zealand \\ ${ }^{3}$ The New Zealand Institute for Plant and Food Research Ltd, Lincoln, New Zealand
}

Received 9 September 2009; revised 14 September 2009; accepted 23 September 2009

\begin{abstract}
The development of a rapid, robust and reliable method for extracting plant food materials is important for screening a wide range of plant bioactives for their health benefits. In this study, extractions of bioactive polyphenolic compounds from fruits and vegetables were performed using a pressurised solvent extraction technique. Variables including solvent, extraction temperature and time, and number of extraction cycles, were optimised to develop a rapid and efficient extraction protocol. The resulting extracts were then analysed for antioxidant capacity, total phenolic content and composition. The optimal parameters found were 19:1 methanol/water (95\% methanol) as solvent and three extraction cycles, of 10 minutes at $40^{\circ} \mathrm{C}$ or 2 minutes at $100^{\circ} \mathrm{C}$. High performance liquid chromatography mass spectrometry did not detect any difference in extract composition between low and high temperatures. Extraction at $100^{\circ} \mathrm{C}$ generally gave a moderately higher yield of polyphenolics for some fruit and vegetable extracts but appeared to reduce the antioxidant activity particularly for turnip leaf, elderberry and sour cherry extracts as measured by oxygen radical absorbance capacity assay. We found that all $40^{\circ} \mathrm{C}$ extracts were better at protecting cells from $\mathrm{H}_{2} \mathrm{O}_{2}$-induced cellular damage than their $100^{\circ} \mathrm{C}$ counterparts. The $40^{\circ} \mathrm{C}$ apple puree and elderberry extracts were about 2 fold and $\mathbf{1 . 7}$ fold more effective, respectively, than extracts prepared at $100^{\circ} \mathrm{C}$. Our results demonstrated that pressurised solvent extraction technique with careful parameter selection can be used as a quick method for screening the health benefits of plant food materials.
\end{abstract}

Keywords: Antioxidant; Accelerated Solvent Extraction; Cytoprotection; Polyphenolics

\section{INTRODUCTION}

The consumption of fruits and vegetables is generally accepted to improve health and wellbeing, as well as reducing the risk of atherosclerotic heart disease [1], neuronal degeneration [2], and cancer [3] by inhibiting various stages of tumour initiation and proliferation [4]. These benefits are thought to be associated with the presence of polyphenolic compounds in fruits and vegetables [5-7], such as those in apples, berries and green leafy vegetables. Feng and co-workers [8] showed that cyanidin-3-rutinoside could selectively kill leukemic cells by inducing oxidative stress. They also suggested that this compound could be used in cancer therapy, as it is widely available in fruits such as black raspberry. Apple phenolic compounds have also been shown to protect human low-density lipoprotein LDL from being oxidised, which may help to prevent cardiovascular disease [9].

The desire to extract nutrients and nutraceuticals from plant materials as functional food ingredients has prompted a continuing search for economically and ecologically feasible extraction technologies. Traditional solid-liquid extraction methods require a large quantity of solvent and are time consuming. The large amount of solvent used not only increases operating costs but also causes additional environmental problems.

Accelerated solvent extraction (ASE) is a fully automated technique that uses common solvents to rapidly extract solid and semisolid samples. ASE operates at temperatures above the normal boiling point of most solvents, using pressure to keep the solvents in liquid form during the extraction process. Pressure allows the extraction cell to be filled faster, helps to force liquid into the pores and to keep the solvent liquid at operating temperatures. ASE is considered as a potential alternative technique to conventional atmospheric pressure methods, for the extraction of polar compounds [10]. Compared with conventional solvent extraction, there is a dramatic decrease in the amount of solvent and extraction time required for ASE [11]. The development of a rapid and 
robust extraction method is essential, particularly when studying and comparing the phenolic composition of fruit extracts, food material or other by product such as that done by Spigno and colleagues [12] on grape marc. Recently, ASE has been developed for extracting phytochemicals from various fruit and vegetable samples [13-15]. The ASE method is gaining in popularity, because of its practicality, speed and ability to process samples automatically using different solvents, pressures and temperatures under nitrogen. ASE extraction can be carried out in minutes, compared with the hours required for conventional methods such as Soxhlet extraction. A rapid extraction maximises sample throughput and would be expected to minimise phytochemical degradation [13].

The aim of the present paper is to verify the possibility of using, instead of traditional extraction procedures, ASE, in order to reduce time, cost of analysis, and waste solvent. This technique uses conventional liquid solvents at elevated temperatures and pressures to achieve quantitative extraction from solid and semisolid samples in a short time and with a small amount of solvent. Here, we report an optimised extraction protocol that is applicable to a diverse range of fruit and vegetable materials, and demonstrate that temperature is a critical extraction parameter, because increasing extraction temperature improves extraction efficiency but appears to increase phytochemical degradation only moderately. Careful choice of conditions is at least as important with ASE as with conventional extraction methods. We have also compared three rapid assays for assessing polyphenolic or antioxidant content of the extracts.

\section{MATERIALS AND METHODS}

All extractions, colorimetric assays and high performance liquid chromatography (HPLC) analyses of plant extracts were carried out in duplicate. The results shown in this study are reported as the mean values and were taken from the result of two separate experiments.

\subsection{Materials}

Quercetin dihydrate was purchased from Acros Organic (New Jersey, USA) and rutin trihydrate from Fluka, BioChemika (Buchs, Switzerland). Annexin V-FITC and binding buffer were obtained from BD Biosciences (San Diego, CA). Folin-Ciocalteu reagent, sodium carbonate and hydrogen peroxide were obtained from $\mathrm{BDH}$ Chemicals (Poole, England, UK). All other chemicals were purchased from Sigma-Aldrich Inc., (St. Louis, $\mathrm{MO}$,

USA).4-[3-(4-iodophenyl)-2-(4-nitrophenyl)-2H-5-tetraz olio]-1, 3-benzene disulfonate (WST-1 reagent) was obtained from Roche (Basel, Switzerland). All solvents used were of HPLC grade. Water used in experiments was deionized (MilliQ). The human neuroblastoma SH-
SY5Y cells were obtained from the American Type Culture Collection (ATCC, Manassas, VA, USA).

\subsection{Plant Materials}

Apple puree (Malus x domestica, Pacific Beauty ${ }^{\mathrm{TM}}$ (Sciearly)) was selected for preliminary trials on extraction method development and optimisation. These apples were harvested in February 2005 from a HortResearch orchard in Hawke's Bay, New Zealand. Five additional local fruits and vegetables were selected for the main study. These were: turnip leaf (Brassica campestris 'Barkant'; $8.5 \mathrm{~kg}$ ), elderberry (Sambucus nigra; $5.0 \mathrm{~kg}$ ), sour cherries (no stone; Prunus cerasus, 'Fanal'; $5.0 \mathrm{~kg}$ ), swede leaf (Brassica napus 'Aparima Gold'; $8.5 \mathrm{~kg}$ ) and apple puree (Malus x domestica, 'Red Delicious'; $5.0 \mathrm{~kg}$ ). The elderberries were collected in March 2005 in Mosgiel New Zealand, whereas sour cherries were collected in April 2005 in Otematata, Waitaki Valley, New Zealand. The turnip and swede leaf samples were collected in May 2005 from the Crop and Food Research Station in Gore, New Zealand. 'Red Delicious' apples were harvested in April 2005 from a HortResearch orchard in Hawke's Bay, New Zealand. After collection, the samples were immediately frozen, freeze dried and milled using a domestic coffee grinder (Coffee and spice grinder, Breville CG2B, Australia), then stored in heat-sealed, gas-impermeable foil bags under vacuum at $-20^{\circ} \mathrm{C}$ until needed.

\subsubsection{Preparation of Pacific Beauty ${ }^{\mathrm{TM}}$ (Sciearly) and 'Red Delicious' Apple Puree}

Apple purees from both cultivars were prepared similarly. Twenty-five apples (approximately $5.0 \mathrm{~kg}$ ) were selected randomly from the harvested batches. Apples were sliced into quarters, cored and then stored in cold water prior to blanching for approximately 6-7 min until the core temperature reached $90^{\circ} \mathrm{C}$. The blanching step was done in order to stop the browning process of the apple slices before processing into puree could be done. The blanched slices were crushed using a pilot-scale screw press (Model 3600, Brown International Corporation, Covina, CA) to produce the puree, which was freeze dried using a pilot-scale freeze dryer (W.G.G Cuddon Ltd, New Zealand).

\subsection{Accelerated Solvent Extraction (ASE)}

Extraction of the plant materials was performed using an accelerated solvent extractor (ASE300) unit (Dionex Corp., Sunnyvale, CA). The ASE apparatus pumps solvent into the extraction cell, pressurises it, holds the solvent in the cell at a controlled temperature and time (termed "static cycle"), and then drains it into a collection vessel. The high pressure appears to speed up penetration of the solvent into the sample pores greatly, which makes the extraction much faster and more efficient than conventional atmospheric pressure methods. 
The high pressure also increases the boiling point of the solvent, allowing the use of solvents at temperatures above their atmospheric pressure boiling points. Samples for extraction were prepared by mixing the freeze-dried sample powder (4 g) with an equal weight of diatomaceous earth $\left(\right.$ Celite $\left.^{\mathbb{Q}}\right)$, which was then packed into the $(34 \mathrm{~mL})$ extraction cells. The use of Celite ${ }^{\circledR}$ was found to be essential, particularly for samples that were high in sugar, as they were hygroscopic and tended to aggregate. It also allowed a more even distribution of the sample within the cell [13].

\subsection{Optimisation of Extraction Parameters}

Preliminary trials were conducted using apple pomace (Malus x domestica, Pacific Beauty ${ }^{\mathrm{TM}}$ (Sciearly) as a model sample. Extraction conditions in the preliminary trials were adopted from Alonso-Salces et al. [13] using 90 seconds purging of $\mathrm{N}_{2}$ and $60 \%$ flush volume. Parameters tested were: choice of solvent (ethanol (EtOH); water; 100, $95,80 \%$ aq. methanol $(\mathrm{MeOH}))$, temperature $(40,100,130$ and $\left.160^{\circ} \mathrm{C}\right)$, duration $(2,5,10$ or 15 minutes) and number (1-4) of static cycles, allowing the use of solvents at temperatures above their atmospheric pressure boiling points. Extraction efficiency was evaluated using the Folin total phenolics assay (Section 2.8). On this basis, the optimum conditions chosen for the remaining experiments were 3 static cycles of either 10 minutes at $40^{\circ} \mathrm{C}$ or 2 minutes at $100^{\circ} \mathrm{C}$, using $95 \%$ aq. $\mathrm{MeOH}$ as the solvent. The remaining experiments were carried out to determine the better of the two protocols arising from the preliminary study, and to evaluate the quality of the extracts in more detail using Liquid Chromatography Mass Spectrometry (LCMS) and both chemical and cell-based antioxidant assays.

\subsection{Processing of Extracts for Storage}

About $70 \mathrm{~mL}$ of extract was produced from each sample replicate. All extracts were made up to a standard volume of $100 \mathrm{~mL}$, and concentrated to $25 \mathrm{~mL}$ under a stream of nitrogen gas using a RapidVap ${ }^{\circledR}$ concentrator unit (model 79100-01, LabConco Corporation, Kansas City, MO). Samples were then aliquotted into freeze dryer vials $(10 \mathrm{ml}$ Stopcock vial, Crown Scientific, Australia) and further concentrated under vacuum using the centrifugal concentrator (model 78100-01, LabConco Corporation, Kansas City, MO). Finally, extract aliquots were freeze dried (Telstar Cryodos-80, Telstar Industrial S.L., Spain) to remove residual water and were stored under vacuum at $-80^{\circ} \mathrm{C}$ prior to analyses.

\subsection{HPLC-MS Analysis Procedure}

Dried samples were prepared for analyses to make approximately $10 \mathrm{mg} / \mathrm{mL}$ into two $1.5 \mathrm{~mL}$ Eppendorf tubes for each sample. One tube was extracted with $1 \mathrm{~mL}$ of $15 \%$ acetic acid in methanol for anthocyanin analysis while the other tube was extracted with $1 \mathrm{~mL}$ of $85 \%$ (v/v) methanol/water for analysis of other flavonoids and phenolic acids. Samples were dissolved by vortex mixing and then centrifuged at $20817 \mathrm{~g}$ for 10 minutes. Samples were diluted as necessary to fall within a suitable linear dynamic range for the detectors used.

The LCMS system consisted of a Thermo Electron Corporation (San Jose, CA) Finnigan Surveyor MS pump, Finnigan MicroAS auto-sampler, Finnigan Surveyor PDA detector and a ThermaSphere TS-130 column heater (Phenomenex, Torrance, CA). The system was fitted with a Synergi-HydroRP C18 column $(250$ x $2.1 \mathrm{~mm}$, Phenomenex). A $5 \mu \mathrm{L}$ aliquot of each sample was separated with a mobile phase flowing at $250 \mu \mathrm{L} / \mathrm{min}$, consisting of $0.1 \%$ formic acid in water (A) and $0.1 \%$ formic acid in acetonitrile (B). A gradient was applied from $100 \%$ (A), held for 5 minutes, to $50 \%$ (B) at 45 minutes, $80 \%$ (B) at 50 minutes, held for 5 minutes, then returned to the starting conditions over 5 minutes before being re-equilibrated for 10 minutes. The eluent was scanned by photodiode array detector (PDA) from 160-600 $\mathrm{nm}$ and analysed by ESI-MS (electrospray) in the positive mode for acetic acid/methanol samples and negative mode for methanol/water extracts. Parent masses from m/z 120-2000 were selected for $\mathrm{MS}^{2}$ fragmentation, followed by the first and second most intense ions from $\mathrm{MS}^{2}$ undergoing $\mathrm{MS}^{3}$, followed by these two most abundant ions each being fragmented to the $\mathrm{MS}^{4}$. Parent ions were excluded for $15 \mathrm{sec}-$ onds after daughter ion fragmentation data collection. Data were processed with the aid of Xcalibur ${ }^{\mathbb{R}} 2.0$-SUR1 (Thermo Electron corporation).

\subsection{Total Phenolic Determination}

Total phenolic content of the extracts was measured using the Folin Ciocalteu colorimetric method [16], using catechin as the standard. Results were then calculated as $\mathrm{mg}$ catechin equivalent per gram of fresh sample. All samples were analysed in duplicate.

\subsection{FRAP Antioxidant Assay}

The ferric-reducing antioxidant potential (FRAP) assay was performed using a published method [17]. All samples were analyzed in triplicate and Trolox standards between $25-250 \mu \mathrm{M}$ and a blank were included in each run. The antioxidant capacity of each extract was calculated as Trolox equivalents from the linear regression formula obtained from a series of corresponding Trolox standards. Finally results were converted to $\mu \mathrm{mol}$ Trolox equivalents per gram of fresh sample.

\subsection{ORAC Antioxidant Assay (Hydrophilic)}

The oxygen radical absorbance capacity (ORAC) assay was performed using a published procedure [18]. All samples were analyzed in triplicate and Trolox standards between 50-180 $\mu \mathrm{M}$ and a blank was included in each run. The antioxidant capacity of each extract was determined 
Table 1. Results from preliminary trials using Pacific Beauty ${ }^{\mathrm{TM}}$ (Sciearly) apple puree as a model to establish optimum extraction conditions using an accelerated solvent extraction method $(\mathrm{n}=2)$. TPC (Total Polyphenolic Concentration) is expressed as mg catechin eq./g FW. (FW: fresh weight).

\begin{tabular}{|c|c|c|c|c|c|c|}
\hline $\begin{array}{l}\text { Parameter } \\
\text { tested }\end{array}$ & Solvent & Concentration & $\mathbf{T}\left({ }^{\circ} \mathbf{C}\right)$ & $\begin{array}{l}\text { Static time } \\
\quad(\mathrm{min})\end{array}$ & $\begin{array}{l}\text { Static } \\
\text { cycle }\end{array}$ & $\begin{array}{c}\text { TPC } \\
(\mathrm{mg} / \mathrm{g} \text { FW) }\end{array}$ \\
\hline \multirow{3}{*}{ Solvent type } & $\mathrm{MeOH}$ & absolute & 40 & 5 & 2 & $1.19 \pm 0.049$ \\
\hline & EtOH & absolute & 40 & 5 & 2 & $0.89 \pm 0.022$ \\
\hline & Water & $100 \%$ water & 40 & 5 & 2 & $0.71 \pm 0.016$ \\
\hline \multirow{6}{*}{$\begin{array}{c}\text { Solvent } \\
\text { concentration }\end{array}$} & $\mathrm{MeOH}$ & absolute & 40 & 5 & 2 & $1.12 \pm 0.057$ \\
\hline & & $95 \%$ & 40 & 5 & 2 & $1.40 \pm 0.021$ \\
\hline & & $80 \%$ & 40 & 5 & 2 & $1.28 \pm 0.028$ \\
\hline & & absolute & 40 & 5 & 2 & $0.87 \pm 0.043$ \\
\hline & $\mathrm{EtOH}$ & $95 \%$ & 40 & 5 & 2 & $0.96 \pm 0.013$ \\
\hline & & $80 \%$ & 40 & 5 & 2 & $0.94 \pm 0.012$ \\
\hline \multirow{4}{*}{$\begin{array}{c}\text { Temperature } \\
\left({ }^{\circ} \mathbf{C}\right)\end{array}$} & \multirow{4}{*}{$\mathrm{MeOH}$} & $95 \%$ & 40 & 5 & 2 & $1.28 \pm 0.028$ \\
\hline & & $95 \%$ & 100 & 5 & 2 & $1.50 \pm 0.021$ \\
\hline & & $95 \%$ & 130 & 5 & 2 & $1.50 \pm 0.042$ \\
\hline & & $95 \%$ & 160 & 5 & 2 & $1.67 \pm 0.028$ \\
\hline \multirow{5}{*}{ Static time } & \multirow{5}{*}{$\mathrm{MeOH}$} & $95 \%$ & 40 & 5 & 2 & $1.20 \pm 0.008$ \\
\hline & & $95 \%$ & 40 & 10 & 2 & $1.23 \pm 0.042$ \\
\hline & & $95 \%$ & 40 & 15 & 2 & $1.18 \pm 0.028$ \\
\hline & & $95 \%$ & 100 & 2 & 2 & $1.41 \pm 0.021$ \\
\hline & & $95 \%$ & 100 & 5 & 2 & $1.53 \pm 0.039$ \\
\hline \multirow{8}{*}{ Static cycle } & \multirow{8}{*}{$\mathrm{MeOH}$} & $95 \%$ & 40 & 10 & $1^{\text {st }}$ cycle & $0.86 \pm 0.028$ \\
\hline & & $95 \%$ & 40 & 10 & $2^{\text {nd }}$ cycle & $0.25 \pm 0.049$ \\
\hline & & $95 \%$ & 40 & 10 & $3^{\text {rd }}$ cycle & $0.12 \pm 0.028$ \\
\hline & & $95 \%$ & 40 & 10 & $4^{\text {th }}$ cycle & $0.006 \pm 0.0005$ \\
\hline & & $95 \%$ & 100 & 2 & $1^{\text {st }}$ cycle & $1.20 \pm 0.018$ \\
\hline & & $95 \%$ & 100 & 2 & $2^{\text {nd }}$ cycle & $0.32 \pm 0.042$ \\
\hline & & $95 \%$ & 100 & 2 & $3^{\text {rd }}$ cycle & $0.14 \pm 0.028$ \\
\hline & & $95 \%$ & 100 & 2 & $4^{\text {th }}$ cycle & $0.004 \pm 0.0002$ \\
\hline
\end{tabular}

by comparing the area under the curve with that of a blank sample and was calculated as Trolox equivalents. Results were converted to $\mu \mathrm{mol}$ Trolox equivalents per gram of fresh sample.

\subsection{Cytoprotection Assay}

\subsubsection{Cell Culture and Treatment of Human Neuroblastoma SH-SY5Y Cells}

The human neuroblastoma SH-SY5Y cells were cultured in Dulbecco's modified Eagle medium nutrient mixture F12 ham (DMEM-F12) supplemented with $10 \%$ FBS at $37^{\circ} \mathrm{C}$ in humidified air with $5 \% \mathrm{CO}$. SH-SY5Y cells were used in the undifferentiated state. The SH-SY5Y cells were plated in 24-well plates at a concentration of 2 $\times 10^{5}$ cells $/ \mathrm{mL}$ with or without various concentrations of extracts. After $24 \mathrm{~h}$ of incubation, cells were harvested and stained with both annexin V-FITC and propidium iodide and subjected to flow cytometric analysis of cell death as described previously $[19,20]$. The cell death index (CDI) was calculated from the percentage of the viable cells and damaged cells (both apoptotic and necrotic). The cytoprotective effects of extracts were measured by the inhibition of $\mathrm{H}_{2} \mathrm{O}_{2}$-induced total cell death. The median effective concentration $\left(\mathrm{EC}_{50}\right)$ values were calculated through dose-response curves of the- concentration of test extract against the percentage of inhibition as described previously $[19,20]$. The cytotoxic effects of extracts were assessed using WST-1 cell survival assays with the concentrations used in the cytoprotection experiments.

\section{RESULTS AND DISCUSSIONS}

\subsection{Preliminary Optimisation of ASE Conditions}

Methanol was found to be the best solvent for extraction of polyphenolic compounds from apple pomace (Table 1). $\mathrm{MeOH}$ extracted approximately $25 \%$ more polyphenolics than ethanol and $40 \%$ more than water. Addition of water (up to $5 \%$ ) to both $\mathrm{MeOH}$ and $\mathrm{EtOH}$ increased the extraction efficiency by up to $20 \%$ and $9 \%$, respectively.

Extraction temperatures between $40^{\circ} \mathrm{C}$ and $130^{\circ} \mathrm{C}$ did not result in any detectable changes in the composition of the extract, as determined by HPLC. Extraction at $160^{\circ} \mathrm{C}$, however, showed evidence of degradation in the HPLC chromatogram. Some peaks diminished in size and new ones appeared (data not shown). Hence, extraction temperatures of $40^{\circ} \mathrm{C}$ and $100^{\circ} \mathrm{C}$ were chosen for comparison in further experiments. The length and number of static 


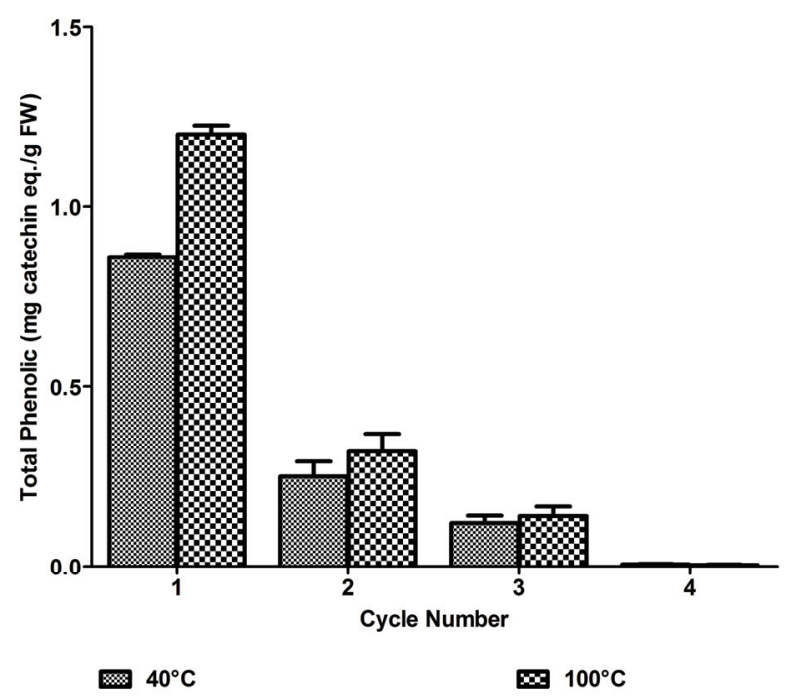

Figure 1. Total phenolic content of Pacific Beauty apple pomace tissue extracted by an accelerated solvent extraction method at $40^{\circ} \mathrm{C}$ and $100^{\circ} \mathrm{C}$ for 10 and 2 minutes respectively using four static cycles.

cycles influenced the extraction efficiency. The optimal conditions were found to be 3 static cycles, either of 10 $\min$ at $40^{\circ} \mathrm{C}$ or $2 \mathrm{~min}$ at $100^{\circ} \mathrm{C}$ (Figure 1, Table 1). Most of the phenolic compounds ( $\sim 90 \%)$ were extracted by the first 2 cycles and most of the remaining material ( $\sim \%)$ by the third cycle, as measured by the Folin-Ciocalteu assay. A fourth cycle was found not to be necessary. Based on the results above, the operating parameters used in the remainder of this study were: solvent: $95 \%$ methanol, temperature: $40^{\circ} \mathrm{C}$ or $100^{\circ} \mathrm{C}$, purging time: 90 seconds, flush volume: $60 \%$, static time: $10 \mathrm{~min}$ for $40^{\circ} \mathrm{C}$ extraction and $2 \mathrm{~min}$ for $100^{\circ} \mathrm{C}$ extraction and 3 static cycles.

\subsection{Identification of Phenolic Compounds by LC-MS}

Identification and quantification of the major compounds found in the extracts was carried out by LC-MS (Table 2). To help with interpreting the data, structural fragmentation characteristics reported by other researchers were used [21, 22], together with in-house spectra based on reference materials and previously interpreted compounds.

\subsection{1. 'Red Delicious' Apple Puree (Malus X Domestica 'Red Delicious')}

Procyanidins made up a significant proportion of compounds found in the apple puree extracts from both temperature treatments (Table 2). This is in agreement with studies by Giusti et al. [22] and Sudjaroen et al. [23]. Chlorogenic acid (the major individual compound), quercetin glycosides and phloridzin were also abundant and have also been previously reported to be present in apple [24].
3.2.2. Swede Leaf (Brassica Napus 'Aparima Gold') The major compounds in swede leaf were several kaempferol glycosides. Most of these were acylated with sinapic or ferulic acid. The phenolic composition was similar to that found by an earlier study [25]. A previous study by Huang and colleagues [26] found some compounds in the swede leaf samples (also known as rutabaga in the US) that might be responsible for its antioxidant property. Because of lack of reference compounds, they were not able to identify them. However, we were able to identify which compounds were present in the extract analysed in the present study, and they were very similar to those found in the turnip leaf extracts. The three most abundant compounds in the swede leaf extract based on the relative area from the total spectral scan were kaempferol-3-(sinapoyl)-sophoroside-7-glucoside, kaempferol-3-(feruloyl)-sophoroside-7-glucoside and kaempferol-3-sophoroside-7-glucoside respectively.

\subsubsection{Sour Cherry (Prunus Cerasus 'Fanal')}

The major polyphenolic compounds found in the sour cherry extracts were 3-p-coumaroyl and 5-caffeoyl quinates (Table 2). Lesser amounts of rutin, quercetin and isorhamnetin glycosides were also found. Clifford and colleagues [27] reported the presence of chlorogenic acid (3-caffeoyl quinate) and this is also confirmed by our result. Procyanidins are also present in the extracts, in good agreement with previous findings [23,28].

\subsubsection{Turnip Leaf (Brassica Campestris 'Barkant')}

Turnip leaf extracts from both high and low temperature treatment had similar polyphenolic compositions (Table 2). The major components found in the extracts were glycosylated flavonols such as quercetin, kaempferol and isorhamnetin and to a lesser extent, sinapic acid derivatives. The previously reported polyphenolic composition of Brassica rapa (another turnip variety) [29], was similar to that found here. Many of the same compounds were also reported in Brassica oleracea (broccoli) by Vallejo et al. [25]. The presence of sinapoyl-malate was previously reported by Liang et al. [30]. Another prevalent compound found in the turnip leaf extract was kaempferol3-sophoroside-7-glucoside, which was also confirmed by Fernandes et al. [31].

\subsubsection{Elderberry (Sambucus Nigra)}

Anthocyanins were the major phenolic compounds in the elderberry extracts (Table 2). Extracts from both temperature treatments were again similar. High concentrations of cyanidin sambubioside (the major individual component), rutin and 5-caffeoyl quinate were found. These compounds were previously reported by Piraud et al. [32] and Milbury et al. [33].

\subsection{Comparison of the Polyphenolic Profile of Extracts}

There were no detectable differences in the polyphenolic 
Table 2. Identification of some major phenolic compounds found in fruit and vegetable samples extracted by ASE technique from $\lambda=280 \mathrm{~nm}$ chromatograms. Quantification was based on total spectral scan $\lambda=250-600 \mathrm{~nm}$ and expressed as $\mu \mathrm{g} / \mathrm{g} \mathrm{FW}$ sample.

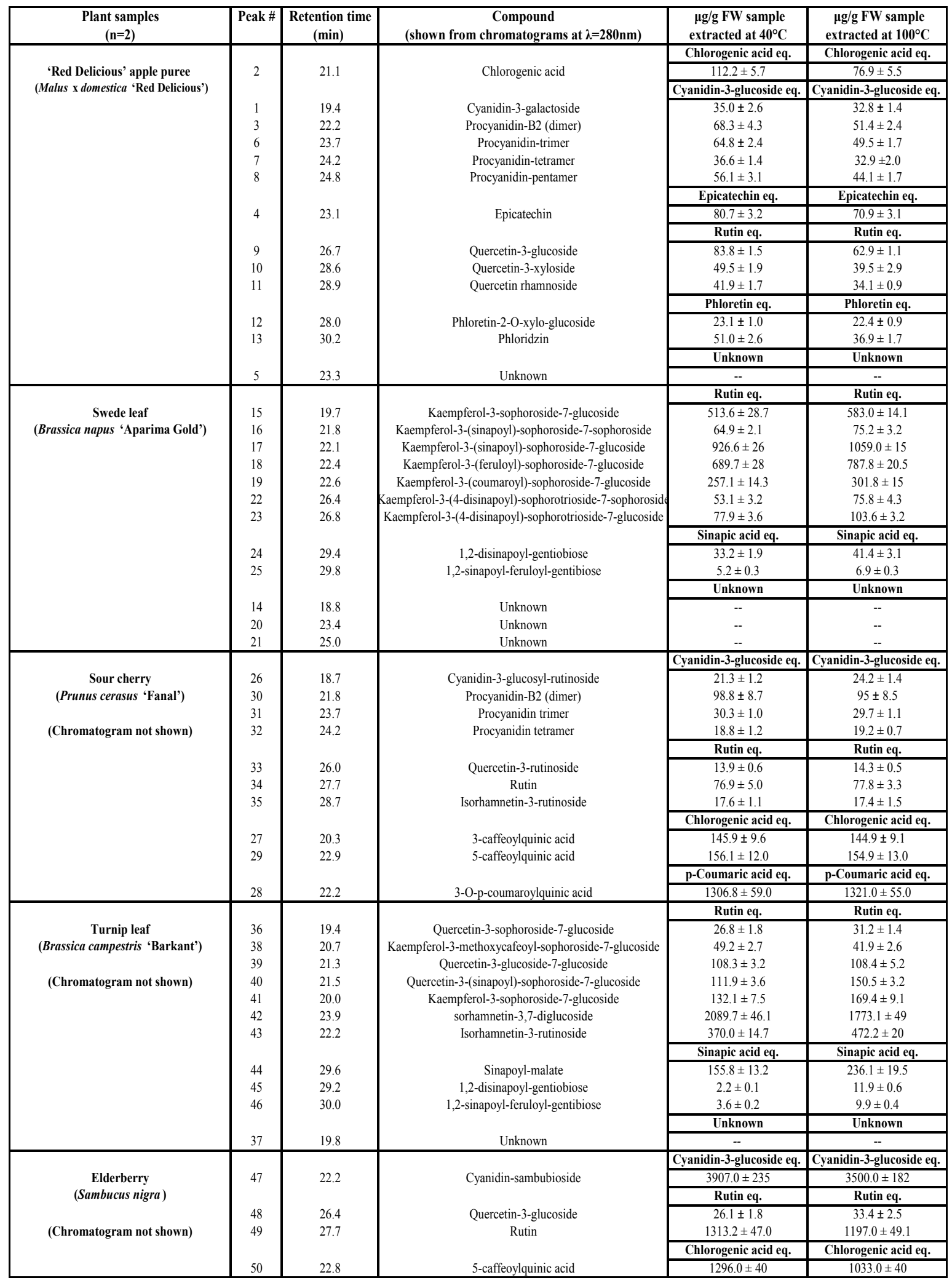



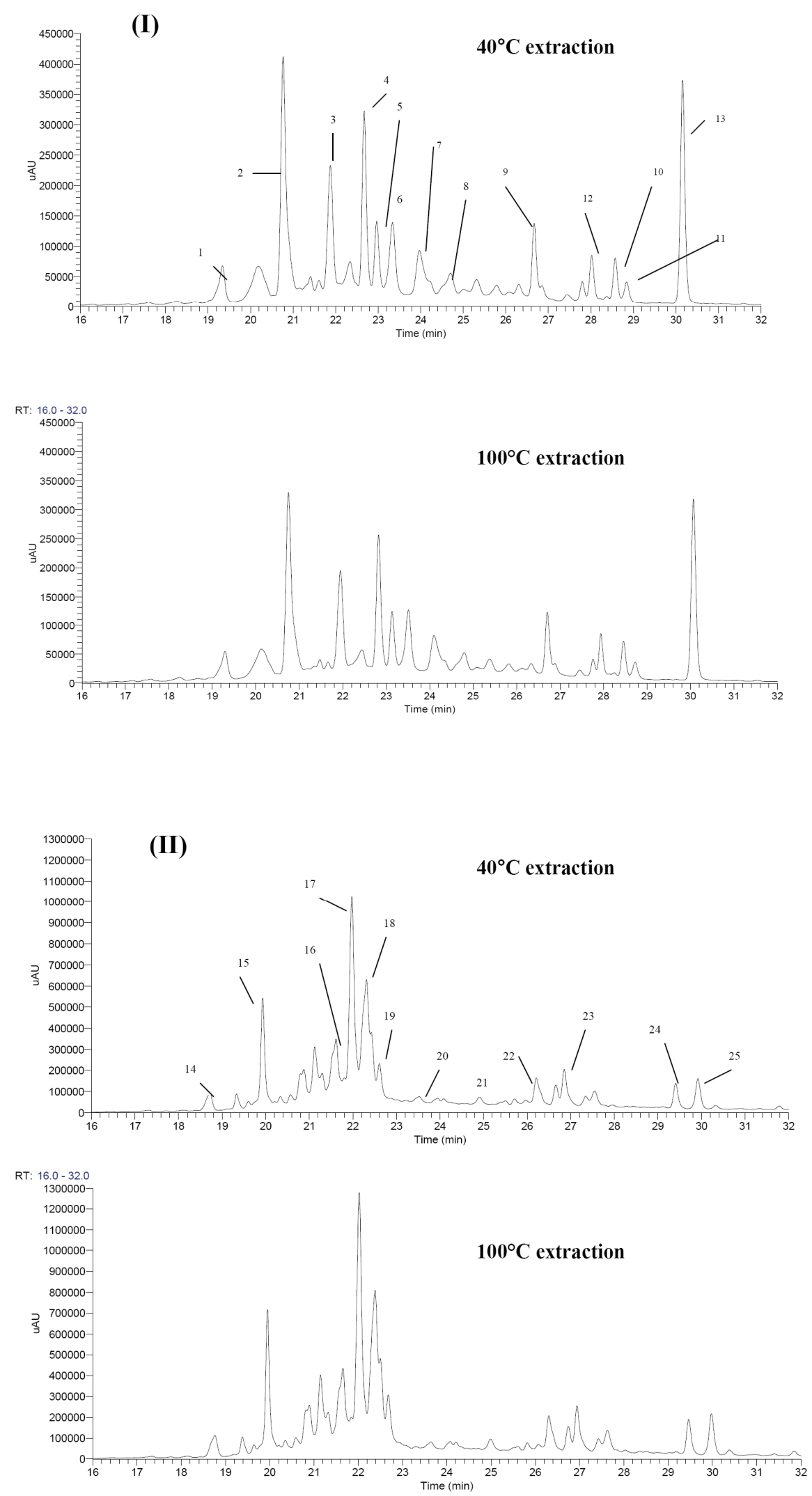

Figure 2. HPLC chromatograms at 280nm of Red delicious apple puree (I) and Swede leaf var. Aparima Gold (II) from accelerated solvent extractions (ASE) at $40^{\circ} \mathrm{C}$ and $100^{\circ} \mathrm{C}$. The sample concentration was $10 \mathrm{mg} / \mathrm{L}$. 


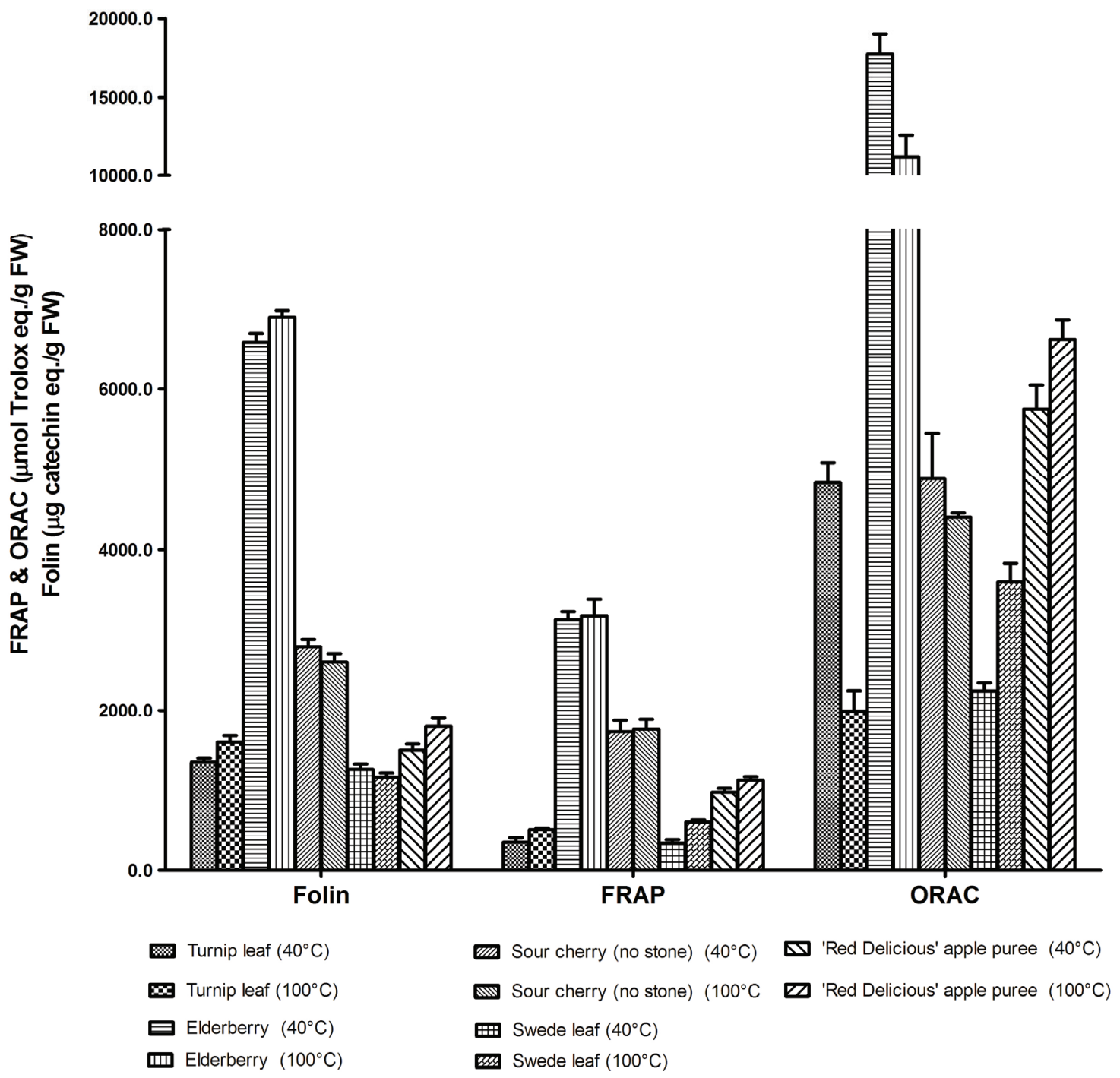

Figure 3. Total phenolic contentby Folin Ciocalteu mathod and antioxidant capacity (measured by FRAP (ferric reducing antioxidant potential) and ORAC (oxygen radical absorbance capacity) methods for fruit and vegetable samples extracted by accelerated solvent extraction (ASE) at $40^{\circ} \mathrm{C}$ and $100^{\circ} \mathrm{C}$. Results are expressed as $\mu \mathrm{g}$ catechin equivalent or $\mu \mathrm{mol}$ Trolox equivalent $/ \mathrm{g}$ fresh weight samples for total phenolic content and antioxidant capacity, respectively.

profiles obtained from ASE prepared using different temperatures, for 'Red Delicious' apple puree or Swede leaf extracts (Figure 2). The same result was obtained from the other plant materials (data not shown). The only noticeable difference was a $20-25 \%$ higher peak intensity at $40^{\circ} \mathrm{C}$ for the apple puree extract, indicating that the lower temperature was, surprisingly, more efficient. If there is increased degradation at $100^{\circ} \mathrm{C}$, it is apparently evenly spread over all compounds. However, extraction of swede leaf showed a different trend to that of apple puree extract, as more phenolics seemed to be released when extraction was carried out at the higher temperature $\left(100^{\circ} \mathrm{C}\right)$.

The polyphenolic composition and concentrations from this study are in good agreement with the USDA database of the flavonoid and proanthocyanidin content of foods (http://www.ars.usda.gov/nutrientdata). As has been discussed by Kroon and Williamson [34], the USDA has now developed databases of polyphenolic compound classes with recommended daily intake (RDI) values, as well as for micronutrients such as vitamins and minerals. Based on the USDA database, the major anthocyanidins found in elderberry were found to be cyanidins, whereas vegetables such as turnip have an appreciable amount of flavonols such as kaempferols and quercetins. ASE extraction appears to provide comparable extraction profiles to manual extraction methods, such as that done by Romani et al. [29] on Brassica plants, and therefore appears 
to be suitable for updating databases of food polyphenolic content in the future.

\subsection{Comparative Total Phenolic Content of Extracts}

Total phenolic content as measured by the Folin-Ciocalteu assay, combined with ASE, is a rapid and convenient means to compare the overall polyphenolic antioxidant content of different plant foods. Elderberry extract stands out, with a total phenolic content 2-4 times higher than the other extracts tested (Figure 3).

Different plant materials behaved differently when extracted at different temperatures. Total phenolic content of turnip leaf, elderberry and red delicious puree extracts were slightly greater when the samples were extracted at $100^{\circ} \mathrm{C}$ than at $40^{\circ} \mathrm{C}$, whereas contents in swede leaf and sour cherry were slightly lower. This may indicate that some polyphenolics from swede leaf and sour cherry are more labile at a higher temperature than those in the other materials extracted. These differences were, however, minor, so on this basis the extraction temperature chosen for comparison of different plant materials could be between $40^{\circ} \mathrm{C}$ and $100^{\circ} \mathrm{C}$.

\subsection{Antioxidant Capacity of Plant Extracts}

The chemical antioxidant activities of the extracts were determined by both the FRAP and ORAC assays. The effect of extraction temperature is more obvious in the FRAP assay than in the total phenolic content assay. Elderberry extract had the highest FRAP value and the trend of the extracts was quite similar to that of total phenolic content (Figure 3). It therefore appears that polyphenolics play a major role in contributing to the metal ion-reducing capacity in these extracts. The FRAP values of all samples measured seemed to be higher when the extraction was carried out at $100^{\circ} \mathrm{C}$. Turnip leaf extract was found to have the lowest antioxidant capacity by this assay.

Elderberry again had the highest value and the qualitative trend of other extracts was similar to the trend identified in the total phenolic content and FRAP results (Figure 3). However, the antioxidant capacities of the elderberry and turnip extracts prepared at $100^{\circ} \mathrm{C}$ were proportionately smaller than those of extracts prepared at $40^{\circ} \mathrm{C}$; the relationship to total phenolic content was much weaker and extraction temperature had a considerable effect. Elderberry and apple puree extracts had the highest ORAC values overall, compared with those of other extracts. The ORAC value of elderberry was moderately lower and turnip leaf ORAC value was reduced by about half when comparison was made between the $100^{\circ} \mathrm{C}$ and $40^{\circ} \mathrm{C}$ treatments. Little difference was found between ORAC values of sour cherry extracts prepared at low and high temperatures. These differences are probably explained by both differences in lability of compounds with high ORAC capacity and the presence of compounds other than polyphenolics with significant ORAC capacity.

\subsection{Cytoprotection Assay}

\subsubsection{Cytotoxicity of Extracts}

The cytotoxicities of these extracts were tested on SH-SY5Y cells at different concentrations for 24 hours using the WST-1 assay. All extracts produced at either temperature did not affect the viability of human neuroblastoma SHSY5Y cells within the concentration range used (data not shown).

\subsubsection{Cytoprotective Effects of Extracts}

The inhibitory effects of test samples on cellular death induced by $\mathrm{H}_{2} \mathrm{O}_{2}$ on human neuroblastoma SH-SY5Y cells were determined.

For extracts at $40^{\circ} \mathrm{C}$, elderberry had the highest protective capacity, followed by apple puree, sour cherry, turnip and swede leaf extracts. For those extracted at $100^{\circ} \mathrm{C}$, elderberry again had the highest protective capacity, followed by sour cherry, apple puree, turnip and swede leaf extracts respectively. This ranking order was the same as with the other assays. The trend of $\mathrm{EC}_{50}$ values was similar to that of the other assays (bearing in mind that a low $\mathrm{EC}_{50}$ value indicates higher cytoprotective capacity; Figure 4). The only significant difference from the other assays was that $40^{\circ} \mathrm{C}$ extracts consistently performed moderately better than the $100^{\circ} \mathrm{C}$ extracts. Based on the results reported here, it appears that there is relatively little to choose between these four antioxidant assays to combine with ASE as a means of rapidly comparing the antioxidant potential of plant foods. The results of all four assays correlate very closely, with the possible exception of the ORAC assay, which is qualitatively similar but shows some quantitative differences.

\section{CONCLUSIONS}

Results indicated that different fruit and vegetable extracts prepared at low and high temperatures behaved differently when analysed for their total phenolic contents and antioxidant capacities. The polyphenolic compositions of the ASE extracts in this study agree well with those reported in literature on the same plant materials. Elderberry extract was found to have the highest polyphenolic content and antioxidant capacity, followed by sour cherry, red delicious apple puree and the two vegetable samples. The four rapid assays used to evaluate the extracts (Folin total phenolics, FRAP, ORAC and cytoprotection), all ranked the five extracts similarly, which possibly indicates that polyphenolics are the major antioxidants in the extracts and are responsible for most of the antioxidant capacity. The effect of extraction temperature was more obvious in results from the ORAC antioxidant assay, particularly for turnip and elderberry extracts. However, all extracts prepared at $40^{\circ} \mathrm{C}$ performed better in the cell-based antioxidant assay. This study has shown 


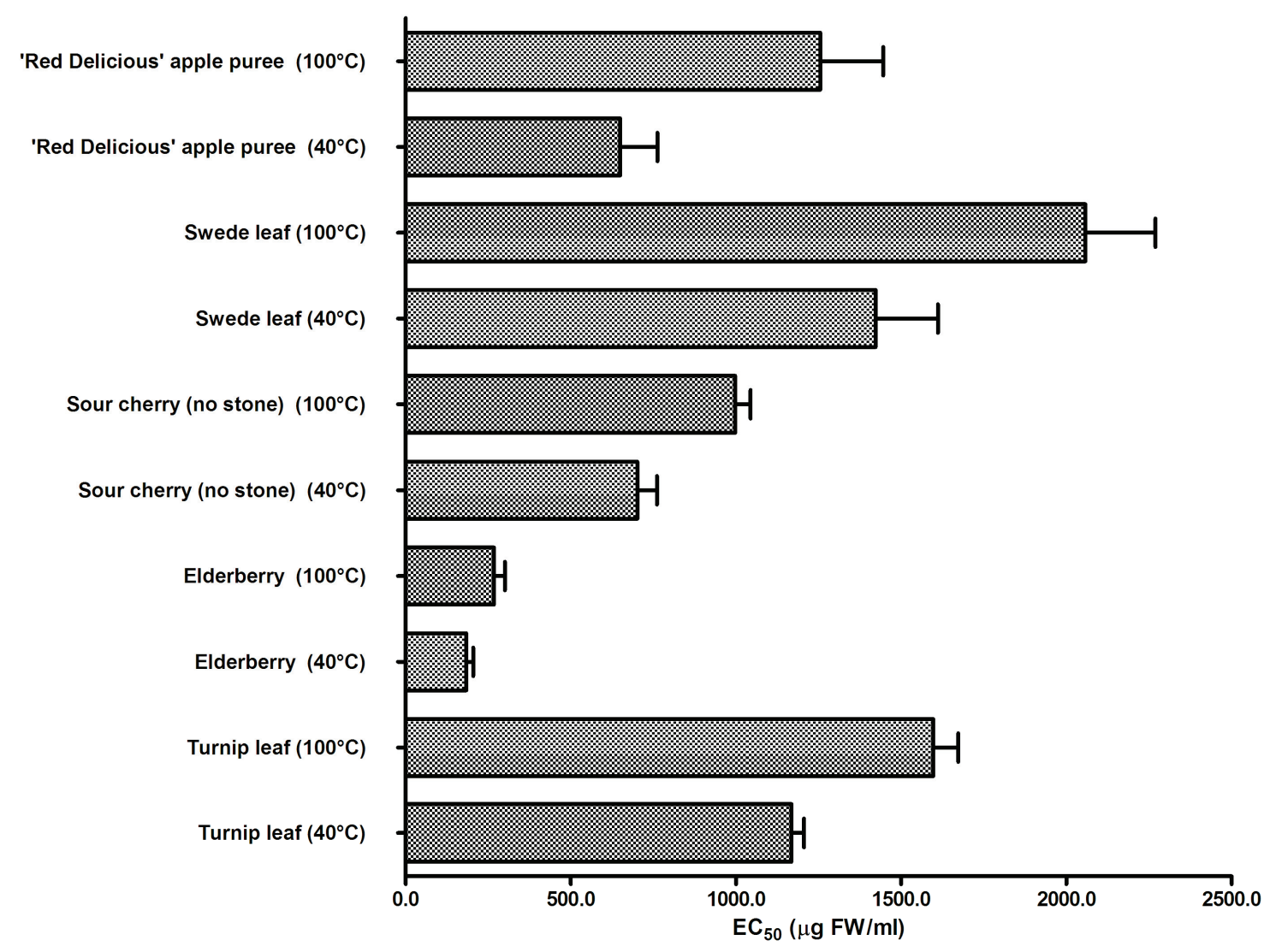

Figure 4. Protective effects $\left(\mathrm{EC}_{50}\right)$ of extracts against $\mathrm{H}_{2} \mathrm{O}_{2}$-induced death of SH-SY5Y cells. After incubation, cells were stained with both annexin V-FITC and PI and analyzed by flow cytometry. Results are expressed as $\mathrm{EC}_{50}$ values with standard deviations from the mean of two separate determinations.

that accelerated solvent extraction, combined with HPLC, antioxidant and cytotoxicity testing, is a useful tool for rapid screening of plant extracts for comparison of the abundance of compounds thought to be beneficial to human health.

\section{ACKNOWLEDGMENTS}

This work was funded by the Foundation for Research Science and Technology (Wellness Foods Programme, Contract C06X0405). We thank Joyce Au and Rosheila Vather for their contribution in doing the antioxidant assays, Tom Orchiston for sample collection, Ms Teresa Wegrzyn, Dr Denise Hunter and Dr Jeffrey Greenwood for checking and the helpful discussions on the manuscript.

\section{REFERENCES}

[1] M. N. Diaz, B. Frei, J. A. Vita, J. F. Keaney, (1997) Mechanisms of disease: Antioxidants and atherosclerotic heart disease. New Engl J Med, 337, 408-416.

[2] Y. Christen, (2000) Oxidative stress and Alzheimer disease. Am J Clin Nutr., 71, 621s-629.

[3] B. N. Ames, L. S. Gold, W. C. Willett, (1995) The causes and prevention of cancer. Proc Natl Acad Sci USA., 92,
5258-65, 0027-8424 (Print).

[4] S. Kuntz, U. Wenzel, H. Daniel, (1999) Comparative analysis of the effects of flavonoids on prolifertion, cytotoxicty and apoptosis in human colon cancer cell lines. Eur J Nutr, 38, 133-142.

[5] C. Bosetti, L. Spertini, M. Parpinel, P. Gnagnarella, P. Lagiou, E. Negri, S. Franceschi, M. Montella, J. Peterson, J. Dwyer, A. Giacosa, C. La Vecchia, (2005) Flavonoids and breast cancer risk in Italy. Cancer Epidemiol Biomarkers Pre, 14, 805-808, 1055-9965.

[6] M. Rossi, E. Negri, R. Talamini, C. Bosetti, M. Parpinel, P. Gnagnarella, S. Franceschi, L. Dal Maso, M. Montella, A. Giacosa, C. La Vecchia, (2006) Flavonoids and colorectal cancer in Italy. Cancer Epidemiol Biomarkers Prev, 15, 1555-1558, 1055-9965.

[7] A. Tavani, L. Spertini, C. Bosetti, M. Parpinel, P. Gnagnarella, F. Bravi, J. Peterson, J. Dwyer, P. Lagiou, E. Negri, C. La Vecchia, (2006) Intake of specific flavonoids and risk of acute myocardial infarction in Italy. Public Health Nutr, 9, 369-374, 1368-9800.

[8] R. Feng, H. M. Ni, S. Y. Wang, I. L. Tourkova, M. R. Shulin, H. Harada, X. M. Yin, (2007) Cyanidin- 3-rutinoside, a natural polyphenol antioxidant, selectively kills leukemic cells by induction of oxidative stress. J Biol Chem, 282, 13468-13476.

[9] D. A. Pearson, C. H. Tan, J. B. German, P. A. Davis, M. E. 
Gershwin, (1999) Apple juice inhibits human low density lipoprotein oxidation. Life Sci, 64, 1913-1920.

[10] R, M. Alonso-Salces, A. Barranco, E. Corta, L. A. Berrueta, B. Gallo, F. Vicente, (2005) A validated solid-liquid extraction method for the HPLC determination of polyphenols in apple tissues - Comparison with pressurised liquid extraction. Talanta, 65, 654-662.

[11] B. E. Richter, B. A.Jones, J. L. Ezzell, N. L. Porter, N. Avdalovic, C. Pohl, (1996) Accelerated solvent extraction: A technique for sample preparation. Ann Chem, 68, 1033-1039.

[12] G. T. L. Spigno, D. M. De Faveri, (2007) Effects of extraction time, temperature and solvent on concentration and antioxidant activity of grape marc phenolics. J Food Eng, 81, 200-208.

[13] R. M. K. E. Alonso-Salces, A. Barranco, L. A. Berrueta, B. Gallo, F. Vicente, (2001) Determination of polyphenolic profiles of basque cider apple varieties using accelerated solvent extraction. J Agric Food Chem, 49, 3761-3766.

[14] X. Wu, G. R. Beecher, J. M. Holden, D. B. Haytowitz, S. E. Gebhardt, R. L. Prior, (2004) Lipophilic and hydrophilic antioxidant capacities of common foods in the United States. J Agric Food Chem, 52, 4026-4037.

[15] X. Wu, G. R. Beecher, J. M. Holden, D. B. Haytowitz, S. E. Gebhardt, R. L. Prior, (2004) Development of database for total antioxidant capacity in foods: A preliminary study. J Food Comp Anal, 17, 407-422.

[16] V. L. Singleton, R. Orthofer, R. M. Lamuela-Raventos, (1999) Analysis of total phenols and other oxidation substrates and antioxidants by means of folin-ciocalteu reagent. Methods Enzymol., 299, 152-178.

[17] N. Deighton, R. Brennan, C. Finn, H. V. Davies, (2000) Antioxidant properties of domesticated and wild rubus species. J Sci Food Agric, 80, 1307-1313.

[18] C. Walton, R. Lentle, G. Reynolds, M. Krugger, T. McGhie, (2006) Anthocyanin absorption and antioxidant status in pigs. J Agric Food Chem, 54, 7940-7946.

[19] J. Zhang, L. Melton, A. Adaim, M. Skinner, (2008) Cytoprotective effects of polyphenolics on H2O2-induced cell death in SH-SY5Y cells in relation to their antioxidant activities. Eur Food Res Technol, 228, 123-131.

[20] J. Zhang, R. A. Stanley, A. Adaim, D. L. Melton, A. M. Skinner, (2006) Free radical scavenging and cytoprotective activities of phenolic antioxidants. Mol Nutr Food Res, 50, 9961005.

[21] N. Fabre, I. Rustan, E. de Hoffman, J. Quetin-Leclercq, (2001) Determination of flavone, flavonol and flavanone aglycones by negative ion liquid chromatography electrospray ion trap mass spectrometry. J Am Soc Mass Spectrom, 12, 707-715.

[22] M. M. Giusti, L. E. Rodriguez-Saona, D. Griffin, R. E. Wrolstad, (1999) Electrospray and tandem mass spectroscopy as tools for anthocyanin characterization. J Agric Food Chem, 47, 4657-4664.

[23] J. F. Sudjaroen, R. Haubner, G. Wurtele, W. E. Hull, G.
Erben, B. Spiegelhalder, S. Changbumrung, H. Bartsch, R. W. Owen, (2005) Isolation and structure elucidation of phenolic antioxidants from tammarind (Tamarindus indica L.) seeds and pericarp. Food Chem Toxicol, 43, 16731682.

[24] F. Sanchez-Rabaneda, O. Jauregui, R. M. LamuelaRaventoz, F. Viladomat, J. Bastida, C. Codina, (2004) Qualitative analysis of phenolic compounds in apple pomace using liquid chromatographycoupled to mass spectrometry in tandem mode. Rapid Comm Mass Spectrom, 18, 553-563.

[25] F. Vallejo, F. A. Tomas-Barberran, F. Ferreres, (2004) Characterization of flavonols in broccoli (Brassica oleracea L. var. italica) by liquid chromatography-UV diode array detection-electrospray by ionisation mass spectrophotometry. J Chromatogr A, 2006, 148-155.

[26] Z. Huang, B. Wang, D. H. Eaves, J. M. Shikany, R. D. Pace, Phenolic compound profile of selected vegetables frequently consumed by African Americns in the southeast United States. Food Chem 2007, 103, 1395-1402.

[27] M. N. Clifford, K. L. Johnston, S. Knight, N. Kuhnert, (2003) Hierarchical scheme for LCMSn identifications of chlorogenic acids. J Agric Food Chem, 51, 2900-2911.

[28] L. Gu, M. A. Kelm, J. F. Hammerstone, Z. Zhang, G. R. Beecher, J. M. Holden, D. B. Haytowitz, R. L. Prior, (2003) Liquid chromatographic/electrospray ionization mass spectrophotmetric studies of proanthocyanidins in foods. J Mass Spectrom, 38, 1272-1280.

[29] A. Romani, P. Vignolini, L. Isolani, F. Leri, D. Heimler, (2006) HPLC-DAD/MS characterization of flavonoids and hydroxycinnamic derivatives in turnip tops (Brassica rapa L. subsp.sylvestris L.). J Agric Food Chem, 54, 1342-1346.

[30] Y. S. Liang, H. K. Kim, A. W. M. Lefeber, C. Erkelens, Y. M. Choi, R. Verpoorte, (2006) Identifications of phenylpropanoids in methyl jasmonate treated Brassica rapa leaves using two dimensional nuclear magnetic resonance spectroscopy. J Chromatogr A, 1112, 148-155.

[31] F. Fernandes, P. Valentao, C. Sousa, J. A. Pereira, R. M. Seabra, P. B. Andrade, (2007) Chemical and antioxidative assessment of dietary turnip (Brassica rapa var. rapa L.). Food Chem, 105, 1003-1010.

[32] M. Piraud, C. Vianey-Saban, K. Petritis, C. Elfakir, J. P. Steghens, A. Morla, D. Bouchu, (2003) ESI-MS/MS analysis of underivatised amino acids: A new tool for the diagnosis of inherited disorders of amino acid metabolism. Fragmentation study of 79 molecules of biological interest in positive and negative mode. Rapid Comm Mass Spectrom, 17, 1297-1311.

[33] P. E. Milbury, G. Cao, R. L. Prior, J. Blumberg, (2002) Bioavailablility of elderberry anthocyanins. Mech Ageing Dev, 123, 997-1006.

[34] P. Kroon, G. Williamson, (2005) Polyphenols: Dietary components with established benefits to health? J Sci Food Agric, 85, 1239-1240. 